\title{
GAMIFICATION: THE NEXT EVOLUTION OF EDUCATION
}

\author{
Vibha Chetan $^{1 *}$, Suman Devadula ${ }^{1,2}$, Rohan Sridhar and Ganesh Sadashiv \\ ${ }^{1}$ PES University, Bangalore, India \\ ${ }^{2}$ MIT World Peace University (MIT-WPU), Pune
}

\begin{abstract}
Education is as effective as learning. Research has shown that learning when experienced is better. Experiencing learning through games can be better. This article inquires whether gamification of content improves learning. For administering this inquiry, a game is designed taking learning content from a course of geography in the curriculum of school students. Using this, findings from a preliminary experimental study conducted across 8-9 year old students of the school in question show that learning, in terms of being able to recall the topics understood, is better for the group that learnt through gamified content. Analysis of data through measures of central tendency across groups is indicative of this improvement. We present our game- based learning environment and findings in this context.
\end{abstract}

Keywords: Gamification, Game based learning, Gamification of Education, Evolution of education

\section{Introduction}

Learning happens, and can always happen informally, before being educated formally with a clear separation of roles of the student (the learner) and teacher (the learned). The knowledge (the learnt) residing with the teacher is presumed to include that required to transfer content (knowledge) effectively. For the purposes of mediating this transfer, the learned often captured their content written in books. From the times of the first 'textbook' made for children to the era of "compulsory primary education" for every child, education has evolved over time. This content traditionally captured in a book. Although learning was happening informally in the absence of written content, the formal approach to learning called 'education', is predominantly identified with the 'textbook'. A textbook has become accepted not only for its content (knowledge) but also, and quite mistakenly so, as a standard reference for testing learning when students are required to reproduce its content within examinations. This has been the traditional growth of formal education. Education, is as effective as can the process of learning be. Given content, learning depends more on the method of content delivery. Despite the emphasis on the role of the teacher or educator in this delivery context, involving students also, as capable, motivated participants and benefiters in the experience of content delivery could be rewarding for their learning eventually. Gamification could be one such way of engaging students.

The purpose of this research is to inquire into the effects of gamification on learning with the assumption that learners will be more involved in the learning experience delivered through games. Although, this resonates with the tested concept of learning through experience, the experience involving a game needs inquiry. Gamification is known to encourage participants to think and take actions based on knowledge, skill and judgement. RISOUK, is a board game designed specific to the course of geography for improving learning. The board game is tested and analyzed through two frameworks, a) Mechanics - Dynamics - Aesthetics framework i.e. MDA Framework \& b) Design - Play - Experience i.e. DPE framework in real time. RISOUK can be used to teach the fundamental topics on resources that are important in Asia.

\section{Research problem}

Students in traditional method of education do not engage in learning actively. 


\section{Research question}

Does gamification of content improve learning?

\section{Significance of the study}

A collection of research on gamification shows that a majority of studies on gamification find that it has positive effects on individuals. (Hamari, et al., 2014). Further to this, it will be interesting to know if such positive effects of gaming can aid the learning when aiding formal methods of teaching. This research hence assumes significance.

\section{Literature Review}

Formal method of teaching is prevalent in most schools in India. A comparison of conventional method of teaching with the Horse Race, emphasizes that the conventional methods are no good for overall growth of the class rather they create only a competing environment (McGee \& Howard, 1998). Formal teaching method involves more theoretical learning rather than application/context-based learning. This is mainly seen during examinations. Examinations conducted in the formal education are of written method. This method of examination does not test students on all aspects of learning. According to Ayeni(Ayeni, 2011)teaching is a continuous process that involves bringing about desirable changes in learners through use of appropriate methods. It is a process that involves investigating, formulating, reasoning and using appropriate strategies to solve problems. Teachers should realize that learning becomes more effective if the students are tasked to perform rather than just asked to remember some information. Students build a better understanding of the main concepts more effectively when they are engaged to solve problems during class activities (Ganyaupfu, 2013).

Today's students are technology savvy and expect to be engaged (Lister, 2015). Technology, generally embodied in gadgets, is able to retain user's attention because it keeps them engaged through activities and games continuously. Activity based learning encourages students to learn real life problems based on applied knowledge and keeps the interest and understanding of the students at its highest level (Khurshid \& Ansari, 2012). Playing games is an activity that most people perform voluntarily from childhood. Games have been shown to be effective in promoting learning (Annetta, et al., 2009). A collection of research on gamification shows that a majority of studies on gamification find it has positive effects on individuals(Hamari, et al., 2014).

\section{Gap Analysis}

Education is as effective as the process of learning can be. Gamification is an effective method of education and encourages participants to act based on knowledge, skill and judgement. In this study, the concept of gamification increases the students' engagement and results in effective learning. The purpose of this study is to show that gamification as a learning aid which helps students to perform better in examinations. The idea to work on a board game was decided based on the following aspects -

- Feasibility in manufacturing board game

- $\quad$ Economical in making

- Enhanced engagement for students

- Better social interaction with friends

\section{Objective}

The objective of this study is to inquire into the effectiveness of gamification of learning with primary school children taken as a sample population. 


\section{Brain Storming}

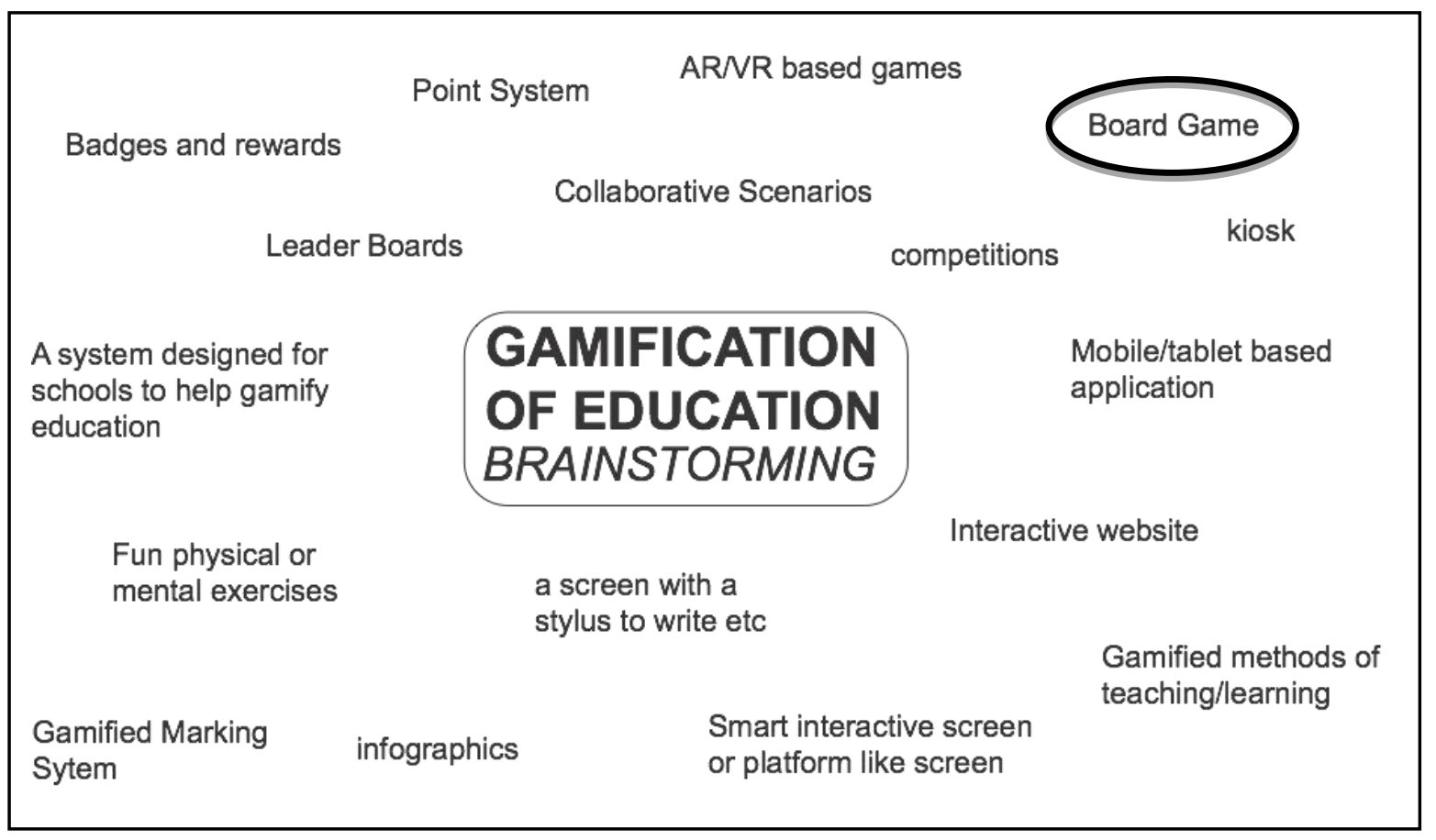

Figure 1: Brainstorming of options through which gamification can be introduced in education

\section{Game Design}

\section{Game Research}

Eleven board games were carefully studied in detail (Scrabble, Pictionary, Survival, Battleship, Monopoly, Formula one, Dungeons and Dragons, Transformers, Othello, Cluedo) before the board game RISOUK was designed. This survey helped in understanding the framework, structure, narrative, rules used to develop these eleven board games and acted as a base for designing RISOUK.

\section{Game Idea}

With insights derived from the above case study, a board game was designed for the purpose of this study. The board game is aimed at teaching students about natural resources, their locations and facts. The board game introduces 8 important resources available in Asia (Rice, wheat, maize, sugarcane, petroleum, iron ore, coal, gold). In this game, all the players travel around Asia and learn where these resources can be found with relevant facts. The game play involves setting up territories and capturing resources while learning about the resources. By doing this, the game integrates gamification with learning, keeping students engaged throughout the learning process. It has positive effects on student's learning as explained by Roland "Playing games can signal the release of dopamine in students' brains when they achieve the goal set out for them, whether they're playing a learning game or something for fun outside of class. Dopamine is a neurotransmitter that controls the reward and pleasure centers of the brain. This can help students enjoy the game and create long-lasting affinity for the subject matter they're studying"(Roland, 2016). The board game requires students to actively participate in order to learn and win the game. This ensures students are concentrating while interacting with the game.

The details of the board game are: 
- Name of the game: RISOUK

- Number of players: 4

- Genre: Educational Board Game

- $\quad$ Age group: 8-12 years

- Aim of the game: To collect resources around the world and establish territories. Players can collect resources when they answer a question correctly. Collecting more resources allows players to conquer territories and win the game.

- Goal: To learn Geography of Asia and all the eight resources while setting up territories and playing the game.

- Learning outcome: Students learn the course better as they are completely engaged in the game play. Adding a fun element into the course.

\section{MDA (Mechanics, Dynamics, Aesthetics) and DPE (Dynamics, Play, Experience) Frameworks}

The structure of the board game was designed using the MDA and DPE framework. Table 1.1 displays the structure designed for Mechanics and Aesthetics using MDA framework. Mechanics are the base components of the game, dynamics are the run-time behavior of the game, aesthetics provoke the emotional response of the player. Table 1.2 displays the structure designed for dynamics using MDA framework. Table 1.3 and 1.4 displays the structure designed for display, play and experience using DPE framework. The design, play, and experience (DPE) framework was created as an expansion of the MDA framework to address the needs of serious game design for learning. To design a game effectively, the designer should first come up with goals for the resulting experience. These goals can be used both to guide the design and to gauge the effectiveness of the design once implemented. Play is greatly influenced by not only the design, but also the player, including his or her cognitive, social, cultural, and experiential background that he or she brings to the given play experience. (Winn, n.d.)

Table 1.1 Mechanics and Aesthetics

\begin{tabular}{ll}
\hline Action & Mechanics \\
\hline Turn & The player can gain resources by performing certain tasks. \\
\hline Action points & Once the player answers the question correctly, gains the points. \\
\hline Capture & $\begin{array}{l}\text { If a player collects all the required resources for the location, then player } \\
\text { captures the location. }\end{array}$ \\
\hline Dice & The dice decide the number of steps the player can play. \\
\hline Movement & Player can move in any direction. \\
\hline Resource Management & $\begin{array}{l}\text { Player has to manage the resources that are collected from many locations to } \\
\text { capture a territory. }\end{array}$ \\
\hline Risk & When the player enters another country, risks the resources collected. \\
\hline Goals & To capture as many countries as possible while learning. \\
\hline
\end{tabular}


Table 1.2 Dynamics using MDA framework

\begin{tabular}{ll}
\hline Behavior & Response \\
\hline Territorial Acquisition & The need for players to acquire as many territories as possible.
\end{tabular}

Survival Each player needs to keep collecting resources to survive.

Contingency $\quad$ Players need to acquire as many territories as possible, but the end result cannot be determined. The player with the max territories wins.

Table 1.3 DPE Framework

\begin{tabular}{lll}
\hline Learning & Story Telling \\
\hline Design & $\begin{array}{l}\text { Content and Pedagogy: Geographical } \\
\text { locations of resources in Asia. }\end{array}$ & $\begin{array}{l}\text { Content and Pedagogy: The game is } \\
\text { played on a map which is mapped with } \\
\text { resources. Player moves the pawn by } \\
\text { rolling the dice and answers questions. }\end{array}$ \\
\hline
\end{tabular}

Peaching: The game teaches players
about resources and their locations. It
indirectly teaches players how to work
$\begin{aligned} & \text { together to ensure the survival of their } \\
& \text { species. }\end{aligned}$$\quad$\begin{tabular}{l}
$\begin{array}{l}\text { Storytelling: Each player can start from } \\
\text { any location in their country. They have } \\
\text { to move around Asia collecting the } \\
\text { required resources for their country to } \\
\text { establish the settlement of their species } \\
\text { in that country. }\end{array}$ \\
\hline
\end{tabular}

Experience Learning: The location of resources in Asia. The players also understand the importance of resource management and the need to conserve and collect resources. It also teaches players how to work together with other players of their species.
Story: A war between aliens and humans to collect maximum resources and save their species.

Table 1.4 DPE Framework (continued)

\section{Game Play}

Design
Mechanics: Players have to move around Asia collecting resources from various countries. The player has to answer the questions on the resources card to claim the resources.

\section{Experience}

User Interface: Easy to understand icons and glyphs. Appropriate colour scheme for children. The Asia map designed to be most accurate and playful. 
Play Dynamics: Strategies to collect the resources before opponent collects.

Interactivity: To pick a resource, answer the question correctly to claim the reward. The players use trackpad to keep a track of the resources collected.

Experience

Affect: Knowledge on location of resources

Engagement: Learning to collect and in Asia. Strategic planning and cooperative manage skill, judgement, competitiveness game play. and value of resources.

\section{Game Play}

In RISOUK, player starts the game by choosing a character. The character determines the team. Each player picks a country card at random which will be the starting point. Player starts the game by rolling the dice and moves accordingly. Player should aim to collect resources to set up a territory in the respective country. When player lands on a resource field on the board, a resource card needs to be picked at random. Answering the question written on the card will allow the player to claim the resource. Answering the questions correctly leads to collection of resources which will in turn allow the players to set up territories and win the game.

\section{Methodology}

\section{Overview}

An experimental study was conducted to test formal method of teaching and by formal method of teaching aided with gamification. Eight and nine-year-old students were chosen to participate in the study. The participants were students studying in an English medium school in Bengaluru, India.For this study the topic "Geography: Important resources in Asia" was taught in both methods. The topic covered geography, food and industrial resources. Information on these resources such as their location and facts are covered during the teaching sessions.

The study consisted of 2 methods of testing - 1. Formal method of teaching 2.Formal method of teaching aided with gamification

1. Formal methodof teaching- For the first stage of the study, students were taught the topic "Geography: Important resources in Asia" using formal method of teaching. This method involved a traditional classroom set up. The content of the topic was taught by the teacher to the students using verbal and pictorial explanation. The content for the study included text, visuals and maps.

2. Formal method of teaching aided with gamification - The second stage of the study involved the gamified aid. The board game RISOUK, is used as the gamified aid in this study. It is designed to aid better understanding of the topic 'Geography: Important resources in Asia.' As it is a four-player game, students played after taking turns at the commencement of teaching session.

\section{Testing}

For the purpose of this study, each method of teaching is categorized into different tests. Thirty students of age group from 8 to 9 years participated in the research. Group A was conducted for 'Teaching using formal method', Group B was conducted for 'Teaching using Gamification'. Each test was conducted for about an hour with the aim of testing the learning capability of the students. The methodical process of the experiment is given below: 
GroupA (control group): - Formal method of teaching -The first test of the study began with a teaching session of the topic, 'Geography: Important resources in Asia.' Students were all provided with study material on the topic consisting of textual content with images. The content covered information on industrial resources such as Iron, Gold, Coal and Steel and food resources such as Wheat, Maize, Rice and Sugarcane. The students were taught from the material designed for the research. Students were allowed to ask questions at any point during and after the teaching session. The teaching session was followed by an examination. The written examination was conducted containing multiple-choice questions, one-word answers, one-line answers and mapping of locations. The aim of the examination is to test the effectiveness of formal method ofteaching on students.

Group B (treatment group)Formal method of teaching aided with gamification - This method is aimed at testing the effectiveness of teaching using gamification as an aid to formal method of teaching. The board game (RISOUK) designed for the purpose of this study was used in the testing. The topic 'Geography: Important resources in Asia.' was taught for this method. Students played the game as a part of the testing. A written examination was conducted containing multiple-choice questions, one-word answers, one-line answers and mapping of locations. A different question paper with the same syllabus was used to assess the effectiveness of teaching using this method.

\section{Measures}

The sample size for the experiment was 30 participants. They were selected using random sampling method. The participants were all from English-medium schools and were in the age group 8-9 years. At the end of each testing, a written exam was conducted in order to evaluate and compare the effectiveness of each method. Furthermore, calculating the mean and variance gave results that compared the effect of learning on each method.

\section{Results}

\section{GroupA (control group) Formal method of teaching:}

Mean marks acquired by 30 students of age group 8-9 years using group A is 17.46.

Variance of marks acquired by 30 students of age group 8-9 years usinggroupA is 13.44.

\section{GroupB (treatment group) Formal method of teaching aided with gamification:}

Mean marks acquired by 30 students of age group 8-9 years using group B is $\mathbf{2 2 . 4 3 .}$

Variance of marks acquired by 30 students of age group 8-9 years using group B is $\mathbf{1 2 . 5 4}$. 


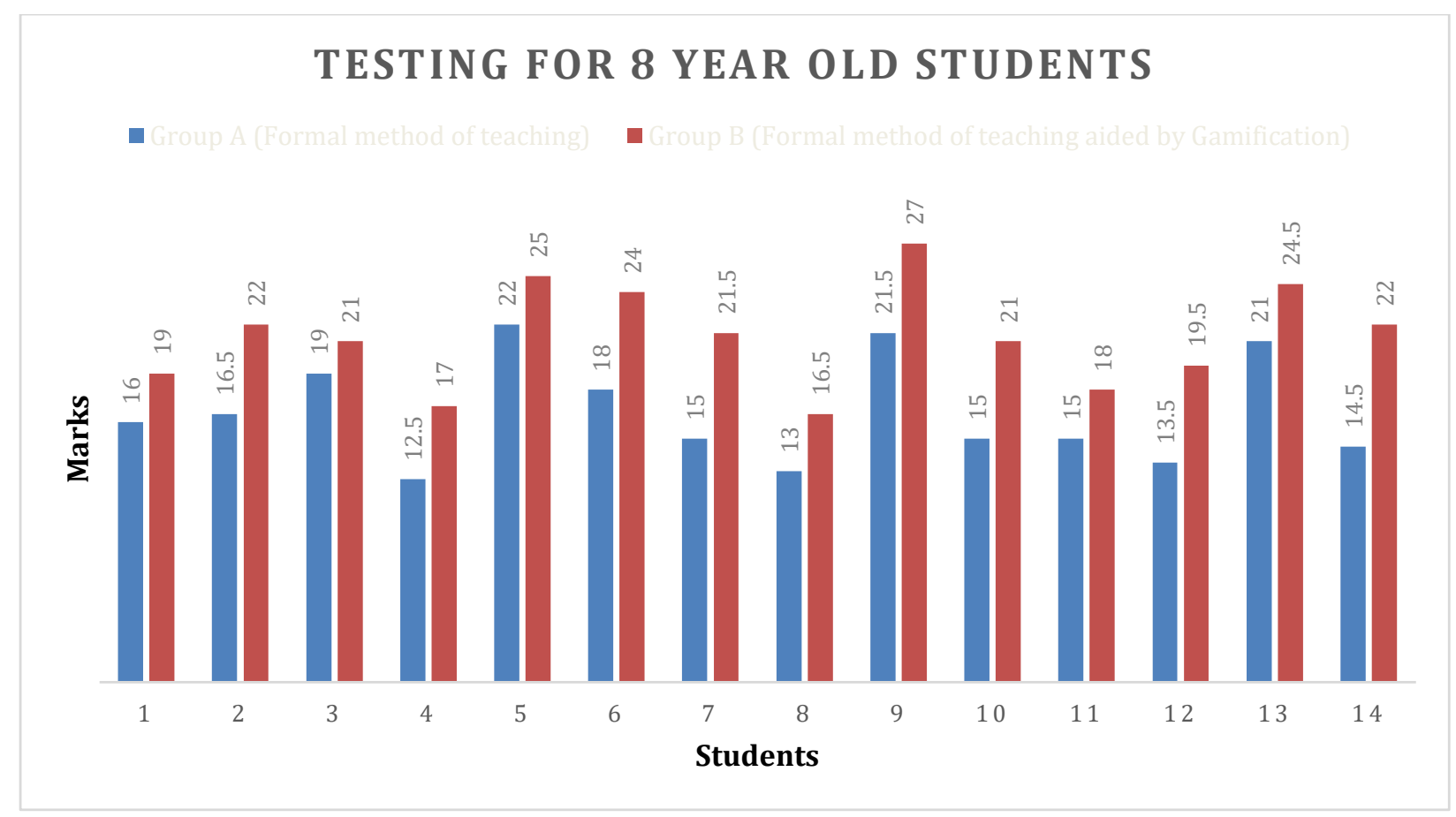

Figure 2: Bar Graph showing data of Group A and Group B for 8-year-old students

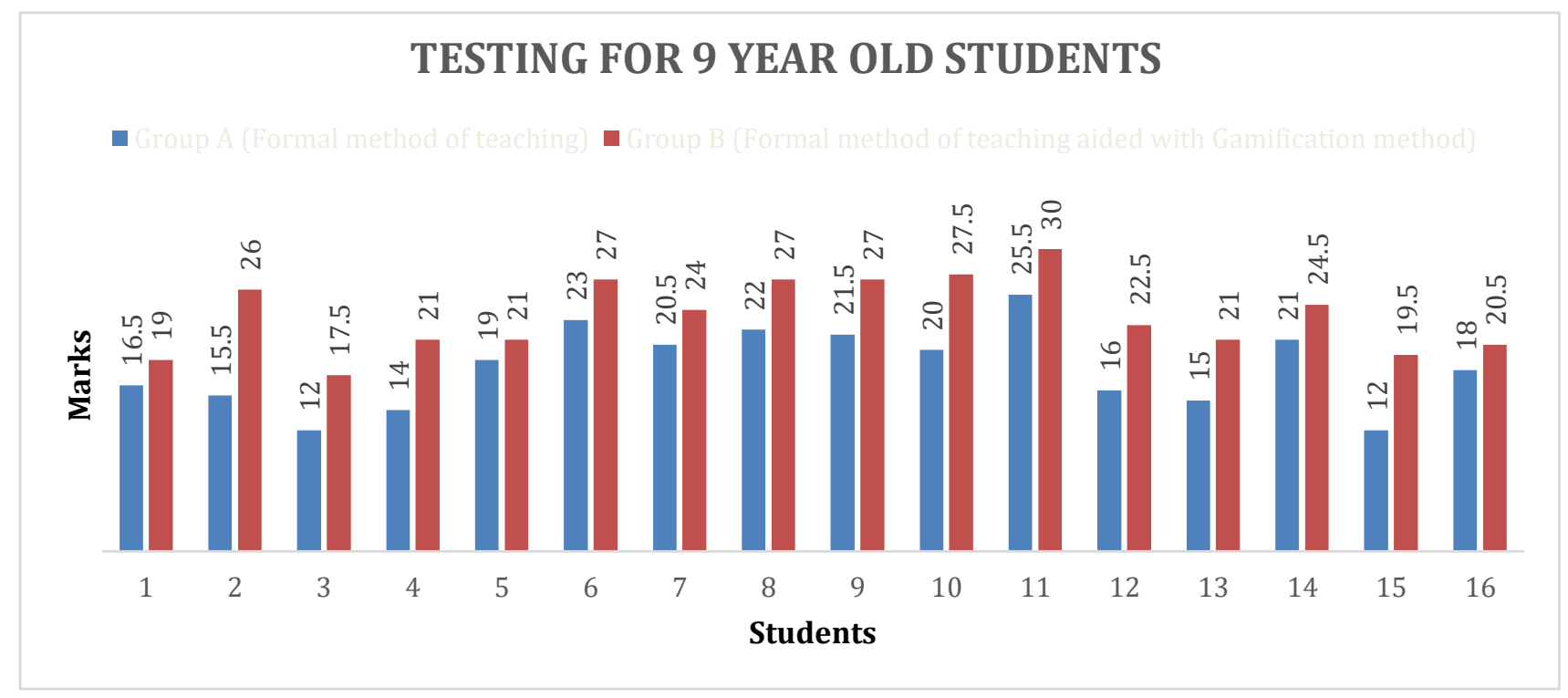

Figure 3: Bar Graph showing data of Group A and Group B for 9-year-old students

\section{Analysis}

According to the research conducted, children in group B showed improved learning and high engagement with the course than the children in group A. Due to increase in engagement in group B, the effectiveness in learning is higher when compared to group A. The study also proves that the variance is lower in group B, which implies that more students are able to learn the course effectively and perform in the examination when compared to group A. 


\section{Observations}

- The children participated in the testing, showed a lot more excitement and interest towards the course as it was learning while playing a game.

- Students accepted to listen to the course and be part of testing as they will be allowed to play the game thereafter. This kind of attention and excitement from the students motivates teachers to teach more effectively.

- The students after playing the game were quick to learn the names and locations of the countries and were able to locate those on the map in examination.

- The idea of learning while playing encourages students to show interest in the course and learn more. Post testing session, many students showed keen interest to pursue and play the game again.

\section{Learning Outcomes}

Scholastic learning and life skills are the learning outcomes of the game. The user learns the descriptive summary of geography in the Asian continent, resources each county produces and facts. The participant also learns life skills like team work, collaboration, strategizing and problem solving.

\section{Discussion and conclusion}

According to the research, by gamification, students are able to show higher levels of interest and engagement in the course, learn effectively and hence, are able to score higher in examinations. Through the results derived, more students scored higher marks when taught usingformal method aided with gamification as opposed to formal method.

As mentioned by Annetta, et al., games have been shown to be effective in promoting learning.(Annetta, et al., 2009) According to our research, gamification has not only promoted learning but has also proven to increase student's engagement with the course and performance in examinations. Students' engagement in the course is important to make learning effective. According to(Ministry of Education, 2016) ,visual aids allow visual learnersto understand the lesson from a different vantage point. The author further states that use of aids such as graphs, charts, flash cards and videos provide learners with visual stimulation which gives the learner the opportunity to interact with the content in a way which allows them to comprehend more easily. However, in our research the findings prove that formal method of teaching aided with gamification observes more engagement from students which gives the learner the opportunity to interact with the content in a way which allows them to comprehend more easily.McGee and Bruce Howardin their work compare conventional method of teaching with the Horse Race and emphasize that the conventional methods are no good for overall growth of the class rather they create only a competing environment (McGee \& Howard, 1998). According to the results of our research, learning through gamification has proven to be effective as it shows increase in mean and decrease in variance when compared to formal/conventional method of learning.

\section{Limitations}

This research has some limitations within which the findings need to be interpreted. Better testing should be conducted to normalize student competence as a variable a priori. This research studies students of age between 8-9 years and other aspects that may vary like gamified learning across other age groups, groups with different gender mixes, groups learning with English as their native language, similar age groups across other curricular systems (Montessori, etc.), groups of different nativities, learning across different courses, learning when administered by different teachers etc. will require further research. 


\section{Future Scope}

RISOUK can act as a concept to encourage and promote new educational board games in the market. New and different approaches can be adopted, to gamify learning depending on the context. Different learning styles such as visual, social, logical, kinesthetic learning can be aided by gamification. Implementing gamification in the curriculum and day to day teaching in schools in India is the primary scope of the research.

\section{Acknowledgement}

We would like to express our gratitude and appreciation to all those who gave us encouragement and opportunity to complete this project. We would like to acknowledge the encouragement we received from the Faculty of Architecture and Design, PES University, Bengaluru, India. We would also like to thank Airaa Academy, Bengaluru, India for helping us conduct our testing in their premises with their enthusiastic students.

\section{References}

Annetta, L. A., Minogue, J., Homes, S. Y. \& Cheng, M.-T., 2009. Investigating the impact of video games on high school students' engagement and learning about genetics. Computers \& Education, 53(1), pp. 74-85.

Anon., n.d. s.1.:s.n.

Ayeni, A. J., 2011. Teachers' Professional Development and Quality Assurace in Nigerian Secondary Schools. World Journal of Education, 1(2), pp. 143-149.

Ganyaupfu, E. M., 2013. Teaching methods and students' academic performance. International Journal of Humanities and Social Science Invention, 2(9), pp. 29-35.

Hamari , J., Koivisto, J. \& Sarsa, H., 2014. Does Gamification work? - A Literature Review of Emperical Studies on Gamification. Hawaii, USA, Proceedings of 47th Hawaii International Conference on System Sciences.

Huotari, K. \& Hamari, J., 2012. Defining Gamification- A service marketing perspective. Tampere, Finland, s.n.

Khurshid, D. \& Ansari, U., 2012. Effects of Innovative Teaching Strategies on Students' Performance. Global Jornal of Human Social Science Linguistics and Education, 12(10), pp. 47-54.

Lister, M. C., 2015. Gamification: The effect on student motivation and performance at the post-secondary level. Issues and Trends in Educational Technology, 3(2), pp. 1-22.

McGee, S. \& Howard, B., 1998. Evaluating Educational Multimedia in the context of Use. Journal of Universal Computer Science, 4(3).

Ministry of Education, G., 2016. Ministry of Education, Guyana. [Online] Available at: https://www.education.gov.gy/web/index.php/teachers/tips-for-teaching/item/2143-why-areteaching-aids-important

[Accessed June 2018].

Roland, J., 2016. Does Gamification Education really improve learning?. [Online] Available at: https://insights.samsung.com/2016/07/19/does-gamification-education-really-improve-learning/ [Accessed 2018].

Winn, B. M., n.d. The Design, Play and Experience Framework. In: R. E. Ferdig, ed. Handbook of Research on Effective electrinic gamining in education. s.1.:Information Science Reference, pp. 1010-1024. 


\section{Appendix}

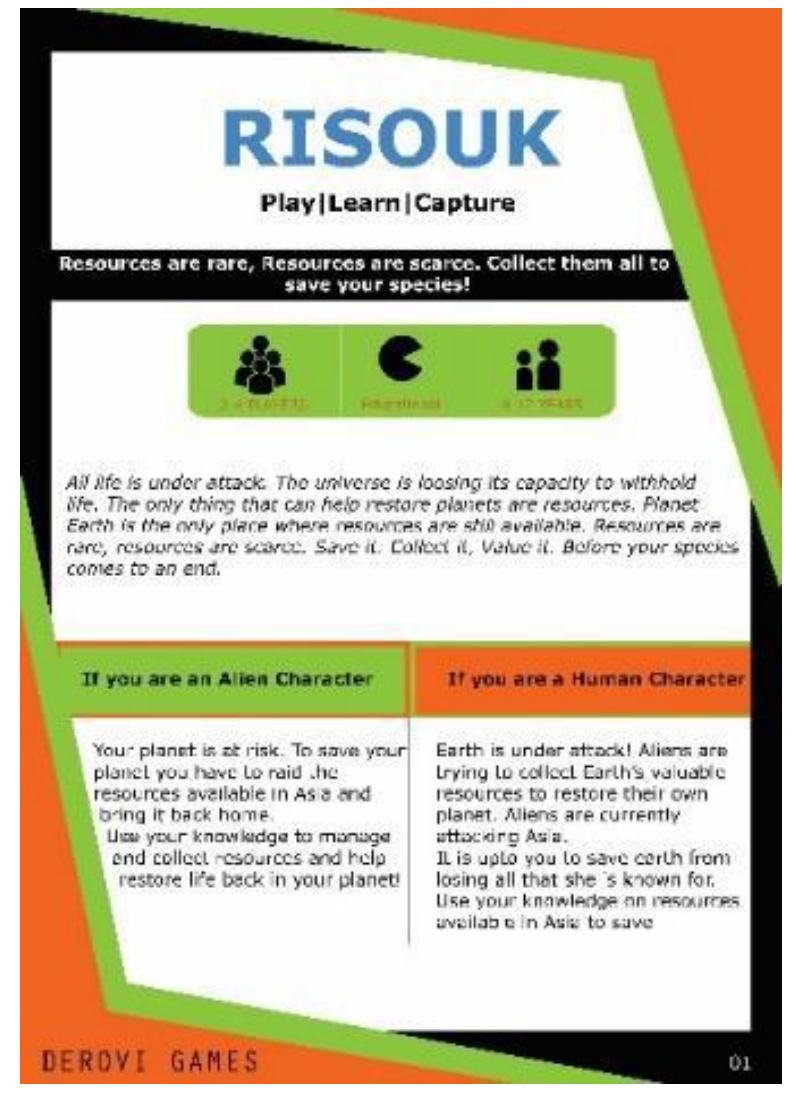

Figure 4: Page-1 of the manaul of board game RISOUK

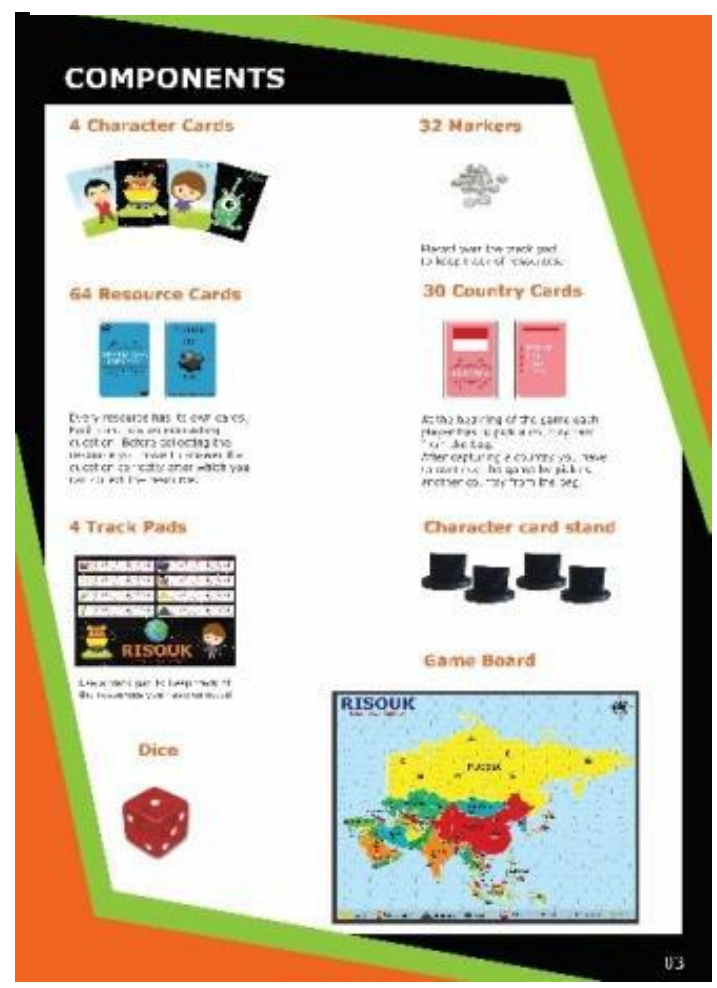

Figure 6: Page-3 of the manaul of board game RISOUK

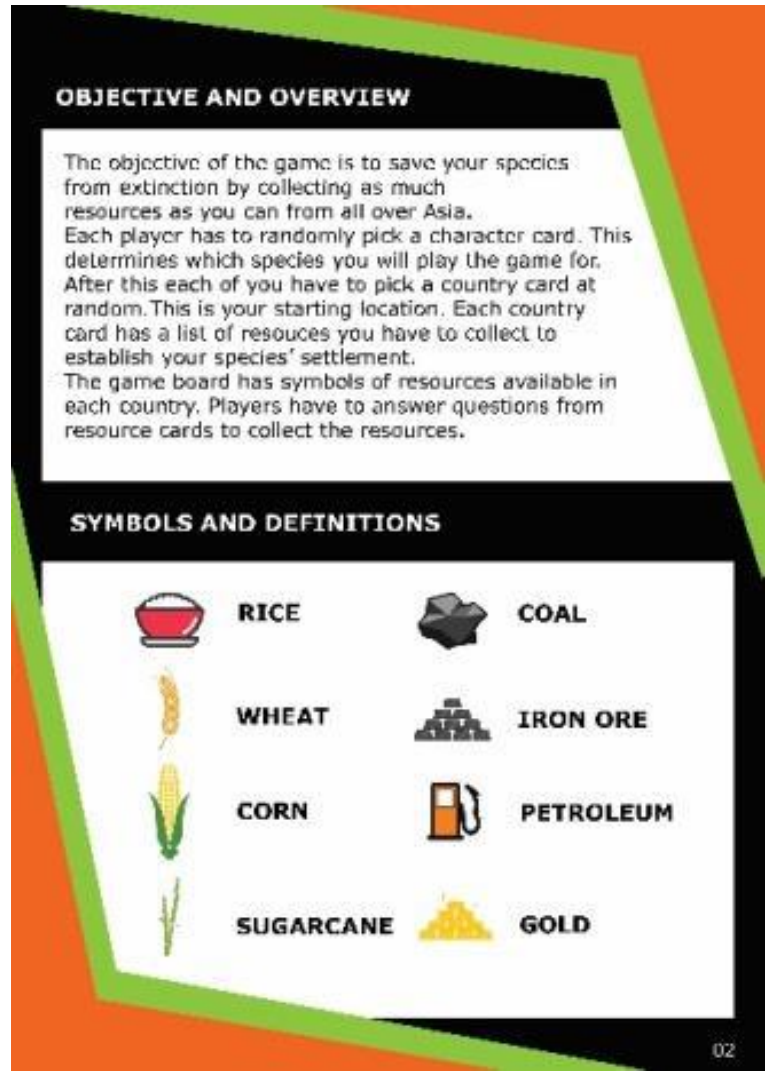

Figure 5:Page-2 of the manaul of board game RISOUK 

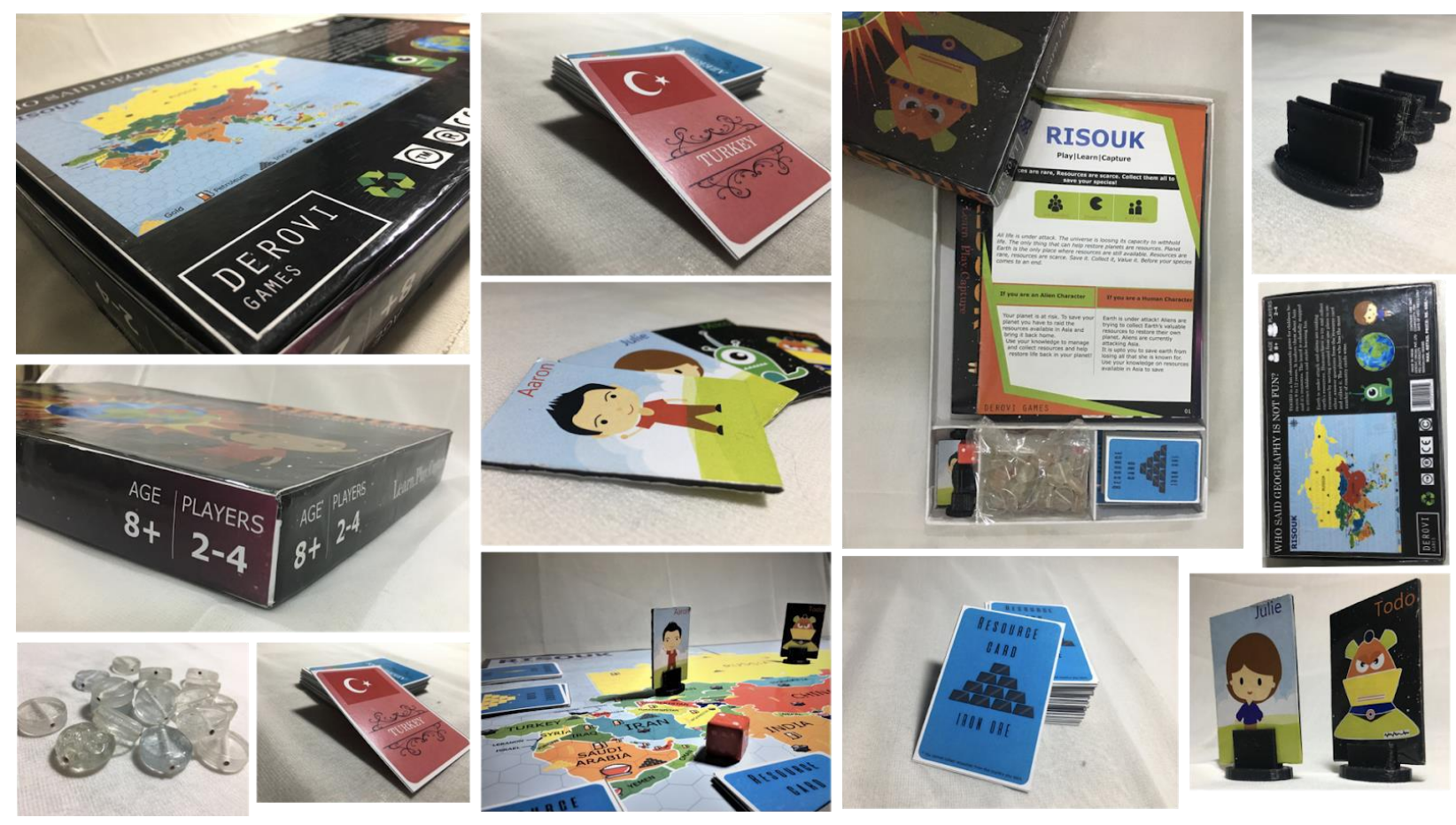

Figure 7: Prototype images of the board game RISOUK 